\title{
Clinical Pharmacology of Levetiracetam in Infants and Children Running title: Levetiracetam in infants and children.
}

Gian Maria Pacifici

Associate Professorof Pharmacology,via Sant'Andrea 32, 56127 Pisa, Italy.

*Corresponding Author: Gian Maria Pacifici, Associate Professorof Pharmacology,via Sant'Andrea 32, 56127 Pisa, Italy.

Received Date: 02 October 2021 | Accepted Date: 18 November 2021 | Published Date: 03 January 2022

Citation: Gian M Pacifici. (2022) Clinical Pharmacology of Levetiracetam in Infants and Children. Journal of Clinical and Laboratory Research. 5(1); DOI:10.31579/2768-0487/054

Copyright: (C) 2022 Gian Maria Pacifici. This is an open-access article distributed under the terms of the Creative Commons Attribution License, which permits unrestricted use, distribution, and reproduction in any medium, provided the original author and source are credited.

\begin{abstract}
Levetiracetam inhibits focal and secondary generalized tonic-clonic seizures. The mechanism of levetiracetam action is not fully understood, however the correlation between binding affinity of levetiracetam and its analogues and their potency toward audiogenic seizures suggest that the synaptic vesicle glycoprotein $2 \mathrm{~A}$ mediates the anticonvulsant effects of levetiracetam. The neural function of the synaptic vesicle $2 \mathrm{~A}$ protein is not fully understood, but binding of levetiracetam to synaptic vesicle glycoprotein $2 \mathrm{~A}$ might affect neuronal excitability by modifying the release of glutamate GABA through an action on vesicular function. Synaptic vesicle glycoprotein $2 \mathrm{~A}$ may plain a role in vesicle recycling following exocytosis of neurotransmitter. In addition, levetiracetam inhibits $\mathrm{N}$-type $\mathrm{Ca}^{2+}$ channels and $\mathrm{Ca}^{2+}$ release from intracellular stores. Levetiracetam may be administered intravenously or orally to infants and children and in children the levetiracetam dose varies according to the child age and body-weight. Levetiracetam is almost completed absorbed after oral administration and levetiracetam is found efficacy and safe in infants and children but it may induce adverse-effects. The levetiracetam elimination half-life is about 6 hours in infants and children, and in children the renal clearance is similar to the non-renal clearance. The prophylaxis, treatment, and trials with levetiracetam have been extensively studied in infants and children. Levetiracetam freely crosses the human placenta and freely migrates into the breast-milk. The aim of this study is to review the levetiracetam dosing, efficacy, safety, adverse-effects, pharmacokinetics, prophylaxis, treatment, and trials and transfer of levetiracetam across the human placenta and levetiracetam migration into the breast-milk.
\end{abstract}

Key words: levetiracetam; dosing; efficacy and safety; adverse-effects; pharmacokinetics; prophylaxis; treatment; trials; placental transfer; breast-milk migration; infants; children

\section{Introduction}

\section{Mechanism of levetiracetam action}

Levetiracetam exhibits a novel pharmacological profile: it inhibits focal and secondary generalized tonic-clonic seizures in the kindling model, yet is ineffective against maximum electroshock - and pentylenetetrazolinduced seizure, Findings consistent with clinical effectiveness against focal and secondary generalized tonic-clonic seizures. The mechanism by which levetiracetam exerts these antiseizure effects is not fully understood. However, the correlation between binding affinity of levetiracetam and its analogues and their potency toward audiogenic seizures suggests that the synaptic vesicle glycoprotein $2 \mathrm{~A}$ mediates the anticonvulsant effects of levetiracetam. The synaptic vesicle glycoprotein $2 \mathrm{~A}$ is an integral transmembrane glycoprotein; expression of human synaptic vesicle glycoprotein $2 \mathrm{~A}$ in hexose transport-deficient yeast shows that the synaptic vesicle glycoprotein $2 \mathrm{~A}$ can function as a galactose transporter. The neural function of the synaptic vesicle glycoprotein 2A protein is not fully understood, but binding of levetiracetam to synaptic vesicle glycoprotein $2 \mathrm{~A}$ might affect neuronal excitability by modifying the release of glutamate GABA through an action on vesicular function. In mice, a missense mutation in the synaptic vesicle glycoprotein $2 \mathrm{~A}$ is reportedly associated with disruption of actionpotential invoked GABA in limbic regions. Synaptic vesicle glycoprotein 2A may play a role in vesicle recycling following exocytosis of neurotransmitter. In addition, levetiracetam inhibits $\mathrm{N}$-type $\mathrm{Ca}^{2+}$ channels and $\mathrm{Ca}^{2+}$ release from intracellular stores [1].

\section{Absorption distribution metabolism and elimination of levetiracetam}

Levetiracetam is rapidly and almost completely absorbed after oral administration and is not bound to plasma proteins. In adults, the plasma elimination half-life is 6 to 8 hours, but may be longer in elderly patients. Ninety-five percent of the drug and its inactive metabolite are excreted in the urine, $65 \%$ of which is unchanged drug, $24 \%$ of the drug is 
metabolized by hydrolysis of the acetamide group. Because levetiracetam neither induces nor is a high-affinity substrate for CYPs or glucuronidation enzymes, it is devoid of known interactions with other antiseizure drugs, oral contraceptives, or anticoagulants [1].

\section{Therapeutic use of levetiracetam}

Levetiracetam is marked for the adjunctive treatment of focal seizures in adults and children, for primary onset tonic-clonic seizures, and for myoclonic seizures of juvenile myoclonic epilepsy. It is available in tablets $(10,25,50,75$, or $100 \mathrm{mg})$, oral solution $(10 \mathrm{mg} / \mathrm{ml})$, or injectable form $(50 \mathrm{mg} / 5 \mathrm{ml})$. Adult dosing is initiated at 500 to $1,000 \mathrm{mg}$ daily and increased every 2 to 4 weeks by $1,000 \mathrm{mg}$ to a maximum dose of 3,000 mg daily. The drug is administered twice-daily. In adults with either refractory focal seizures or uncontrolled generalized tonic-clonic seizures associated with idiopathic generalized epilepsy, addition of levetiracetam to other antiseizure medications is superior to placebo. Levetiracetam also has efficacy as adjunctive therapy for refractory generalized myoclonic seizures. Insufficient evidence is available about its use as monotherapy for focal or generalized epilepsy [1]. Levetiracetam is an anticonvulsant which has been used off-label in infants with difficult to treat seizures. It is a pyrrolidone derivative and is chemically unrelated to other currently available anticonvulsants. Although the exact mechanism of action is unclear, it has been shown to regulate glutamate release and NMDA receptor-mediated excitatory synaptic transmission. Unlike other anticonvulsants it does not induce cell death and apoptosis in the developing brain which might offer a theoretical benefit over older established anticonvulsants. Levetiracetam has a broad antiepileptic activity across different seizure types and syndromes and is licensed in many countries as add-on treatment for partial-onset seizures in children aged $>4$ years. In children and adults, the most common adverse-effects are somnolence and behavioural adverse-effects. Case studies and pharmacokinetic studies in newborn infants have suggested that levetiracetam is also safe in this group but evidence of benefit of randomized trials has yet to be published [2]. Levetiracetam $\left(\right.$ Keppra $\left.^{\circledR}\right)$ is an anticonvulsant and in the neonatal period it has been used as a second line of therapy for seizures refractory to phenobarbital and other anticonvulsants. Serum trough concentrations are not routinely monitored although they may be useful when determining the magnitude of dosing adjustment. Therapeutic concentrations are approximately 10 to $40 \mu \mathrm{g} / \mathrm{ml}$ [3].

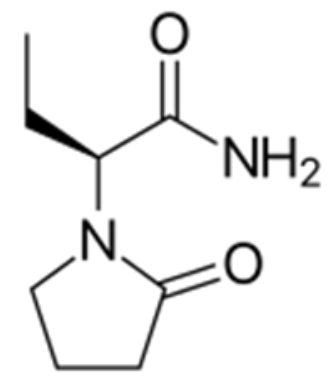

Levetiracetam molecular structure (molecular weight $=170.209$ grams/mole)

\section{Literature search}

The literature search was performed electronically using PubMed database as search engine and the following key words were used: "levetiracetam dosing infants, children", "levetiracetam efficacy safety infants, children", "levetiracetam adverse-effects infants, children", "levetiracetam pharmacokinetics infants, children", "levetiracetam prophylaxis infants, children", "levetiracetam treatment infants, children", "levetiracetam trials infants, children", "levetiracetam placental transfer", and "levetiracetam breast-milk". In addition, the books: The Pharmacological Basis of Therapeutics [1], Neonatal
Formulary [2], NEOFAX ${ }^{\circledR}$ by Young and Mangum [3], and The British National Formulary for Children [4] are consulted.

\section{Results}

\section{Administration schedules of levetiracetam to infants and children}

Administration to infants [2]

Intravenous administration

May be given with or without a loading dose depending on the urgency with which seizure control is needed. Without a loading dose: start with $10 \mathrm{mg} / \mathrm{kg}$ twice-daily increasing followed by $10 \mathrm{mg} / \mathrm{kg}$ over 3 days to 30 $\mathrm{mg} / \mathrm{kg}$ twice-daily. With loading dose: $40 \mathrm{mg} / \mathrm{kg}$ loading dose followed by $10 \mathrm{mg} / \mathrm{kg}$ once-daily (Note: the authors of this study suggested from pharmacokinetic studies that a maintenance dose of $19 \mathrm{mg} / \mathrm{kg}$ eight hourly results in better maintenance of serum levels towards the end of the first week of life).

\section{Oral or enteral administration}

Give $10 \mathrm{mg} / \mathrm{kg}$ daily in one to two divided doses, increase the dose daily by $10 \mathrm{mg} / \mathrm{kg}$ over 3 days to $30 \mathrm{mg} / \mathrm{kg}$ daily (further increases in doses have been reported up to $60 \mathrm{mg} / \mathrm{kg}$ daily).

Administration to children [4]

Oral of intravenous infusion treatment of monotherapy of focal seizures with or without secondary generalisation

Children aged 16 to 17 years. Give initially $250 \mathrm{mg}$ daily for 1 week, and then increase the dose to $250 \mathrm{mg} / \mathrm{kg}$ twice-daily, and then increase the dose in steps of $250 \mathrm{mg}$ twice-daily (maximum per dose $=1.5 \mathrm{mg}$ twice-daily), adjust the dose according to the response, the dose to be increased every 2 weeks.

Oral treatment for adjunctive therapy of focal seizures with or without secondary generalisation

Children aged 1 to 5 months. Give initially $7 \mathrm{mg} / \mathrm{kg}$ once-daily, and then increase the dose in steps of up to $7 \mathrm{mg} / \mathrm{kg}$ twice-daily (maximum per dose $=21 \mathrm{mg} / \mathrm{kg}$ twice-daily), the dose to be increased every 2 weeks.

Children aged 6 months to 17 years (body-weight up to $50 \mathrm{~kg}$ ). Give initially $10 \mathrm{mg} / \mathrm{kg}$ once-daily, and then increase the dose is steps of 10 $\mathrm{mg} / \mathrm{kg}$ twice-daily (maximum per dose $=30 \mathrm{mg} / \mathrm{kg}$ twice-daily) the dose to be increased every 2 weeks.

Children aged 12 to 17 years (body-weight $50 \mathrm{~kg}$ and above). Give initially $250 \mathrm{mg}$ twice-daily, and then increase the dose in steps of 500 $\mathrm{mg}$ twice-daily (maximum per dose $=1.5$ grams twice-daily), the dose to be increased every 2 to 4 weeks.

Intravenous treatment for adjunctive therapy of focal seizures with or without secondary generalisation

Children aged 4 to 17 years (body-weight up to $50 \mathrm{~kg}$ ). Give initially $10 \mathrm{mg} / \mathrm{kg}$ once-daily, and then increase the dose in steps of up to $1 \mathrm{mg} / \mathrm{kg}$ twice-daily (maximum per dose $=30 \mathrm{mg} / \mathrm{kg}$ twice-daily), the dose to be increased every 2 weeks.

Children aged 12 to 17 years (body-weight $50 \mathrm{~kg}$ or above). Give initially $250 \mathrm{mg}$ twice-daily, and then increase the dose in steps of 500 mg twice-daily (maximum per dose $=1.5$ grams twice-daily, the dose to be increased every 2 weeks).

Oral or intravenous treatment for adjunctive therapy of myoclonic seizures and tonic-clonic seizures

Children aged 12 to 17 years (body-weight up to $50 \mathrm{~kg}$ ). Give initially $10 \mathrm{mg} / \mathrm{kg}$ once-daily, and then increase the dose in steps of up to $10 \mathrm{mg} / \mathrm{kg}$ 
twice-daily (maximum per dose $=30 \mathrm{mg} / \mathrm{kg}$ twice-daily), the dose to be increased every 2 weeks.

Children aged 12 to 17 years (body-weight $50 \mathrm{~kg}$ or above). Give initially $250 \mathrm{mg}$ twice-daily, and then increase the dose in steps of 500 mg twice-daily (maximum per dose $=1.5$ grams twice-daily, the dose to be increased every 2 weeks).

\section{Efficacy and safety of levetiracetam in infants and children}

Levetiracetam is a good and safe choice for treatment of neonatal seizures in preterm infants [5]. Levetiracetam is found to be well tolerated and efficacious for the treatment of infants with epilepsy [6]. Levetiracetam is efficacy and safe for infants and children with partial onset seizures [7]. Levetiracetam shows good efficacy, safety and tolerability for the longterm neonatal seizure treatment [8]. Levetiracetam is a safe and effective treatment for neonatal seizures which are unresponsive to phenobarbital [9]. Levetiracetam is an effective, well tolerated, and safe agent for the treatment of a variety of seizure types in infants [10]. Levetiracetam is an efficacious medication in treatment of seizures in the setting of neonatal hypoxic ischemic encephalopathy [11]. Intravenous levetiracetam is an efficacious agent for seizure management in preterm neonates [12]. Levetiracetam treatment is efficacy and safe in treating neonatal seizures suggesting that levetiracetam has anticonvulsant activity in term and preterm infants [13]. Levetiracetam is safe and effective for a wide range of epileptic seizures and epilepsy syndromes and therefore represents a valid therapeutic option in infants and young children affected by epilepsy [14]. The adjunctive use of intravenous levetiracetam is effective and well tolerated in paediatric patients with refractory status epilepticus even in patients younger than 2 years [15]. All responding children were on levetiracetam doses $\geq 30 \mathrm{mg} / \mathrm{kg}$ daily (median $40 \mathrm{mg} / \mathrm{kg}$ daily). No significant adverse-effects of levetiracetam were reported. Levetiracetam is effective and safe adjuvant therapy in children with refractory status epilepticus [16]. In children, intravenous levetiracetam may be effective in various clinical situations requiring intravenous administration of an antiepileptic drug [17]. Intravenous levetiracetam is effective in terminating status epilepticus or acute repetitive seizures and well tolerated in critically ill children [18]. Intravenous administration of levetiracetam is safe and effective for the treatment of acute repetitive seizures and convulsive status epilepticus in children and adolescents [19]. Levetiracetam given twice-daily in children with refractory epilepsy reduces seizure frequency in all types of epilepsy [20]. Intravenous levetiracetam is effective and safe in the treatment of children with acute repetitive seizures [21].

\section{Common or very common adverse-effects caused by levetiracetam in infants and children [4]}

Anxiety, appetitive decreased, asthenia, behavioural abnormal, cough, depression, diarrhoea, dizziness, drowsiness, gastrointestinal discomfort, headache, increased risk of infection, insomnia, mood altered, movement disorders, nausea, skin reaction, vertigo, and vomiting.

\section{Uncommon adverse-effects caused by levetiracetam in infants and children [4]}

Alopecia, concentration impaired confusion, hallucination, leukopenia, muscle weakness, myalgia, paraesthesia, psychotic disorder, suicidal tendencies, thrombocytopenia, vision disorders, and weight changes.

\section{Rare or very rare adverse-effects caused by levetiracetam in infants and children [4]}

Acute kidney injury, agranulocytosis, hepatic disorders, hyponatraemia, neutropenia, pancreatitis, pancytopenia, personality disorders, rhabdomyolysis, severe cutaneous adverse reactions, and thinking abnormal.

\section{Pharmacokinetics of levetiracetam in infants}

Merhar et al. [22] studied the pharmacokinetics of levetiracetam in 18 infants with gestational and postnatal ages of $38 \pm 6$ weeks (range, 2 to 41 ) and 2 days (range, 0 to 32), respectively, and weighed $3.5 \mathrm{~kg}$ (range, 2.0 to 4.4) and levetiracetam was intravenously infused and the initial loading dose ranging from 14.4 to $39.9 \mathrm{mg} / \mathrm{kg}$ and all infants received at least 20 $\mathrm{mg} / \mathrm{kg}$ of phenobarbital before receiving levetiracetam.

\begin{tabular}{|l|l|l|l|}
\hline & Final model & Bootstrap N = 1,000 \\
\hline Parameter & Estimate & Median & 95\%CI \\
\hline Total body clearance (L/h) & 0.097 & 0.093 & $0.06-0.15$ \\
\hline Central distribution volume (L) & 1.96 & 1.89 & $1.83-1.95$ \\
\hline Intercompartmental clearance (L/h) & 1.1 & 0.98 & $0.92-1.04$ \\
\hline Peripheral distribution volume (L) & 0.89 & 0.69 & $0.63-0.75$ \\
\hline Interindividual variability (\%CV) & 4.2 & 0.19 & $0.13-0.25$ \\
\hline Total body clearance & 37.5 & 0.14 & $0.08-0.2$ \\
\hline Central distribution volume & 31.6 & 0.12 & $0.06-0.18$ \\
\hline Intercompartmental clearance & 114 & 1.10 & $1.04-1.16$ \\
\hline Peripheral distribution volume & 24.1 & 0.07 & $0.01-0.13$ \\
\hline Residual variability & 0.028 & 0.11 & $0.05-0.17$ \\
\hline Proportional error (\%CV) & Additive error
\end{tabular}

Table 1: Pharmacokinetic parameters of levetiracetam which are obtained in 18 infants, by Merhar et al. [22].

This table shows that the central distribution volume is larger than the peripheral and there is a remarkable interindividual variability of the pharmacokinetic parameters.
Glauser et al. [23] investigated the pharmacokinetics of levetiracetam in 12 infants and children aged $19.9 \pm 14.16$ months (range, 2.3 to 46.2 ) who received a single oral dose of levetiracetam of $20 \mathrm{mg} / \mathrm{kg}$.

\section{Pharmacokinetics of levetiracetam in infants and children}

\begin{tabular}{|l|l|}
\hline Parameter & Value \\
\hline Peak concentration $(\mu \mathrm{g} / \mathrm{kg})$ & $31.3 \underline{+6.7}$ \\
\hline Peak concentration normalized $(\mu \mathrm{g} / \mathrm{kg})$ & $1.57 \pm 0.34$ \\
\hline Time to reach the peak concentration $(\mathrm{h})$ & $1.4 \pm 0.9$ \\
\hline $\mathrm{AUC}_{0-24 \mathrm{~h}}(\mu \mathrm{g} * \mathrm{~h} / \mathrm{ml})$ & $233 \pm 64$ \\
\hline $\mathrm{AUC}_{0-\infty}(\mu \mathrm{g} * \mathrm{~h} / \mathrm{ml})$ & $248 \pm 75$ \\
\hline
\end{tabular}




\begin{tabular}{|l|l|}
\hline AUC normalized $(\mu \mathrm{g} * \mathrm{~h} / \mathrm{ml})$ & $12.4 \underline{+3.5}$ \\
\hline Absorption-rate constant $\left(\mathrm{h}^{-1}\right)$ & $0.14 \underline{0} 0.04$ \\
\hline Elimination half-life $(\mathrm{h})$ & $5.3 \underline{1.3}$ \\
\hline Total body clearance $(\mathrm{ml} / \mathrm{min} / \mathrm{kg})$ & $1.46 \underline{+0.42}$ \\
\hline Total body clearance $\left(\mathrm{ml} / \mathrm{min} / 1.73 \mathrm{~m}^{2}\right)$ & $53.0 \pm 16.3$ \\
\hline Distribution volume $(\mathrm{L} / \mathrm{kg})$ & $0.63 \underline{+0.08}$ \\
\hline
\end{tabular}

Table 2: Pharmacokinetic parameter of levetiracetam which are obtained in 12 infants and children and levetiracetam was administered orally at a dose of $20 \mathrm{mg} / \mathrm{kg}$. Figures are the mean +SD, by Glauser et al. [23].

AUC $=$ area under the plasma concentration-time curve. Peak concentration normalized and AUC normalized are normalized to a dose of $1 \mathrm{mg} / \mathrm{kg}$.

This table shows that levetiracetam is rapidly absorbed as the absorption rate constant is $0.14 \pm 0.04 \mathrm{~h}^{-1}$ and the time to reach the peak plasma concentration is $1.4 \pm 0.9 \mathrm{~h}$. The levetiracetam distribution volume is lower than the water volume, levetiracetam is rapidly eliminated and there is a remarkable interindividual variability in the pharmacokinetic parameters.
Such variability is accounted by the wide variability of the subject demographic characteristics and also by the concomitant administration of different drugs.

\section{Pharmacokinetics of levetiracetam in children}

Pellock et al. [24] explored the pharmacokinetics of levetiracetam in 15 boys and 9 girls and subjects were aged $9.4 \pm 2.2$ years (range, 5.6 to 12.6) who received a single oral dose of $20 \mathrm{mg} / \mathrm{kg}$ levetiracetam.

\begin{tabular}{|l|l|l|l|}
\hline Parameter & Boys $(\mathrm{N}=15)$ & Girls $(\mathrm{N}=9)$ & Total $(\mathrm{N}=24)$ \\
\hline Creatinine clearance $\left(\mathrm{ml} / \mathrm{min} / 1.73 \mathrm{~m}^{2}\right)$ & $88.7 \pm 26.0$ & $67.0 \pm 24.7$ & $80.6 \pm 27.2$ \\
\hline Peak concentration $(\mu \mathrm{g} / \mathrm{ml})$ & $25.1 \pm 9.0$ & $26.9 \pm 8.4$ & $25.8 \pm 8.6$ \\
\hline Time to reach peak concentration $(\mathrm{h})$ & $2.1 \pm 1.2$ & $2.6 \pm 1.1$ & $2.3 \pm 1.2$ \\
\hline AUC $(\mu \mathrm{g} / \mathrm{h} / \mathrm{ml})$ & $231 \pm 69$ & $257 \pm 87$ & $241 \pm 76$ \\
\hline Absorption-rate constant $\left(\mathrm{h}^{-1}\right)$ & $0.120 \pm 0.022$ & $0.120 \pm 0.024$ & $0.120 \pm 0.022$ \\
\hline Elimination half-life $(\mathrm{h})$ & $6.0 \pm 1.1$ & $6.0 \pm 1.2$ & $6.0 \pm 1.1$ \\
\hline Total body clearance $(\mathrm{ml} / \mathrm{min} / \mathrm{kg})$ & $1.48 \underline{ \pm 0.36}$ & $1.36 \underline{ \pm} 0.37$ & $1.43 \pm 0.36$ \\
\hline Total body clearance $\left(\mathrm{ml} / \mathrm{min} / 1.73 \mathrm{~m}^{2}\right)$ & $77.8 \pm 16.1$ & $64.7 \pm 18.9$ & $72.7 \pm 18.1$ \\
\hline $\begin{array}{l}\text { Cumulative urinary excretion } \\
0-24 \text { hours }(\%)\end{array}$ & $48.2 \pm 11.4$ & $56.7 \pm 15.7$ & $51.9 \pm 13.8$ \\
\hline Renal clearance $(\mathrm{ml} / \mathrm{min} / \mathrm{kg})$ & $0.77 \pm 0.24$ & $0.82 \pm 0.30$ & $0.79 \pm 0.26$ \\
\hline Renal clearance $\left(\mathrm{ml} / \mathrm{min} / 1.73 \mathrm{~m}{ }^{2}\right)$ & $39.4 \pm 9.4$ & $39.6 \pm 16.7$ & $39.5 \pm 12.8$ \\
\hline Non-renal clearance $(\mathrm{ml} / \mathrm{min} / \mathrm{kg})$ & $0.73 \pm 0.32$ & $0.54 \pm 0.31$ & $0.64 \pm 0.32$ \\
\hline
\end{tabular}

Table 3: Pharmacokinetic parameters of levetiracetam which are obtained in 15 boys and 9 girls who received a single oral dose of 20 mg/kg levetiracetam. Figures are the mean \pm SD, by Pellock et al. [24].

$\mathrm{AUC}=$ area under the plasma concentration-time curve.

This table shows that levetiracetam is rapidly absorbed as the absorptionrate constant is $0.120 \pm 0.022 \mathrm{~h}^{-1}$, the time to reach the peak concentration is $2.3 \pm 1.2 \mathrm{~h}$, levetiracetam is rapidly eliminated. The renal clearance of levetiracetam is similar to the non-renal clearance suggesting that

\begin{tabular}{|l|l|l|l|l|}
\hline Parameter & Estimate & \% RSE & 95\% CI & Shrinkage \\
\hline Total body clearance $(\mathrm{L} / \mathrm{h})$ & 1.04 & 1.4 & $1.011-1.069$ & --- \\
\hline Distribution volume $(\mathrm{L})$ & 12.1 & 5.6 & $10.767-13.433$ & --- \\
\hline Absorption-rate constant $\left(\mathrm{h}^{-1}\right)$ & 1.56 & 14.3 & $1.230-1.997$ & --- \\
\hline$\omega \mathrm{Cl} / \mathrm{F}$ & 0.195 & 7.0 & $0.106-0.141$ & 20.05 \\
\hline$\omega \mathrm{V} / \mathrm{F}$ & 0.163 & 45.5 & $1.27-0-175$ & $44.9 \%$ \\
\hline
\end{tabular}

Table 4: Pharmacokinetic parameters of levetiracetam which are obtained in children aged 0.5 to 14 years, by Wang et al. [25].

$\omega \mathrm{Cl} / \mathrm{F}=$ variance of the $\mathrm{Cl} / \mathrm{F} . \omega \mathrm{V} / \mathrm{F}=$ variance of the $\omega \mathrm{V} / \mathrm{F} . \% \mathrm{RSE}=$ $\%$ relative standard error.

This table shows that there is a remarkable interindividual variability of the pharmacokinetic parameters which is accounted by the wide variability of the demographic characteristic of the subjects enclosed in the study. The total body clearance and the distribution volume significantly correlate with the age and body-weight of subjects. In particular, the total body clearance increases with the subject age and body-weight and the distribution volume decreases with the subject age and body-weight.

Prophylaxis with levetiracetam in infants and children levetiracetam is eliminated by kidney and non-renal route. In addition, there is no gender-related difference in the pharmacokinetic parameters.

Wang et al. [25] studied the pharmacokinetics of levetiracetam in children aged 0.5 to 14 years and levetiracetam was orally administered at a dose of 20 to $60 \mathrm{mg} / \mathrm{kg}$.

Levetiracetam is as effective as flunarizine in paediatric migraine Prophylaxis [26]. Levetiracetam and phenytoin have similar safety and effectiveness for the prevention of busulfan-induced seizures in a paediatric hematopoietic cell transplantation population [27]. Levetiracetam is a reasonable alternative to (fos) phenytoin for prophylaxis of early post-haemorrhagic seizures in infants and children [28]. Children receiving prophylaxis with levetiracetam after severe traumatic brain injury have a lower incidence of seizures of $9 \%$ [29].

\section{Treatment of infants and children with levetiracetam}

Very low certainty of evidence suggests that levetiracetam might not be more effective than phenobarbital. Moderate certainty of evidence 
indicates levetiracetam is associated with a lower risk of adverse-events [30]. Levetiracetam is an efficacious medication in treatment of seizures in the setting of neonatal hypoxic ischemic encephalopathy [31]. Levetiracetam is an alternative therapeutic option in neonatal seizures [32]. Levetiracetam monotherapy is effective in treating neonatal seizures [33]. Adjunctive levetiracetam is an efficacious and well-tolerated treatment for partial-onset seizures in infants and young children [34]. Levetiracetam treatment is safe and effective in very paediatric patients with various types of epilepsy [35]. Levetiracetam combined with sodium valproate is effective in the treatment of children with epilepsy, and does not increase the clinical adverse-drug reactions [36]. There are significant differences in controlling seizures between levetiracetam and carbamazepine and the suppression of focal seizure occurs in $87 \%$ of children treated with levetiracetam [37]. Levetiracetam is an anticonvulsant agent with a favourable tolerability profile and a low potential for drug interactions and it is a useful option as adjunctive therapy in paediatric patients with epilepsy [38].

\section{Trials with levetiracetam in infants and children}

Levetiracetam is efficacy in the treatment of neonatal seizures and may be considered as the first-line anticonvulsant in infants with epilepsy [39]. The efficacy of levetiracetam is similar to that of phenytoin as secondline antiseizure medication for paediatric convulsive status epilepticus
[40]. A trial showed that levetiracetam is efficacy and safety for preventing and treating paediatric epilepsy [41]. Levetiracetam is an effective anti-epileptic drug for both adults and children with generalized or partial-onset refractory seizures with a favourable adverse-event profile [42]. Levetiracetam has comparable effects concerning efficacy, tolerability, and adverse-events and levetiracetam is effective as monoand adjunctive-therapy for all types of epilepsy syndromes and seizures in children [43]. A trial showed that levetiracetam is similar to phenytoin in children with convulsive status epilepticus resistant to benzodiazepines [44]. Although levetiracetam is not superior to phenytoin, the results suggest that levetiracetam is an appropriate alternative to phenytoin as the first-choice anticonvulsant agent in the treatment of paediatric convulsive status epilepticus [45]. Two clinical trials confirm that levetiracetam is a broad spectrum anti-epileptic drug with a favourable safety profile in children [46].

\section{Transfer of levetiracetam across the human placenta}

Tomson et al. [47] administered levetiracetam at a dose ranging from 1 to 3 grams daily to 14 pregnant women on the third trimester of pregnancy and measured the concentration of levetiracetam in the maternal and umbilical cord on delivery and 6, 12, 24, and 36 hours after delivery.

\begin{tabular}{|c|c|c|c|c|c|c|}
\hline \multirow[b]{2}{*}{ Value } & \multirow[b]{2}{*}{$\begin{array}{l}\text { Maternal } \\
\text { plasma }\end{array}$} & \multicolumn{5}{|c|}{$\begin{array}{l}\text { Concentration of levetiracetam in the plasma of umbilica } \\
\text { cord at different times after delivery }\end{array}$} \\
\hline & & $\begin{array}{l}\text { At } \\
\text { delivery }\end{array}$ & 6 hours & 12 hours & $\begin{array}{l}24 \\
\text { hours }\end{array}$ & 36 hours \\
\hline Minimum & 24 & 25 & 15 & 16 & 48 & 3 \\
\hline Maximum & 120 & 148 & 88 & 97 & 76 & 26 \\
\hline Mean & 61.3 & 74.5 & 45.6 & 42.4 & 59.0 & 15.4 \\
\hline SD & \pm 9.8 & \pm 14.6 & \pm 8.7 & \pm 8.6 & \pm 8.6 & \pm 2.5 \\
\hline
\end{tabular}

Table 5: Concentrations of levetiracetam in the maternal and umbilical cord at different times after delivery. Figures are the minimum, maximum, mean, and $+S D$, by Tomson et al. [47].

This table shows that levetiracetam freely crosses the placenta and slowly decays in the umbilical cord.

López-Fraile et al. [49] described the transfer of levetiracetam across the human placenta in 5 women at delivery at term of pregnancy. The mean umbilical cord to maternal plasma ratio is 1.21 suggesting the levetiracetam freely crosses the human placenta.

Johannessen et al. [50] administered levetiracetam at doses of 1.5 to 3 grams daily to 3 pregnant women at delivery at the third trimester of pregnancy. The levetiracetam concentration in the maternal and umbilical cord serum levetiracetam concentrations are $155 \pm 65.9$ and $177 \pm 72.8$ $\mu \mathrm{g} / \mathrm{kg}$, respectively, and the umbilical cord to maternal serum ratio of levetiracetam is $1.2 \pm 0.1$.

\section{Migration of levetiracetam into the breast-milk}

Tomson et al. [47] administered levetiracetam at doses of 1 and 3 grams daily to 5 lactating women and measured the concentration of levetiracetam in the maternal plasma in the breast-milk.

\begin{tabular}{|c|c|c|c|c|c|c|}
\hline Value & Days after delivery & $\begin{array}{c}\text { Levetiracetam } \\
\text { conc. in } \\
\text { maternal } \\
\text { plasma }(\mu \mathrm{g} / \mathrm{ml})\end{array}$ & $\begin{array}{c}\text { Levetiracetam } \\
\text { conc. in } \\
\text { breast-milk } \\
\text { before nursing } \\
(\mu \mathrm{g} / \mathrm{ml})\end{array}$ & $\begin{array}{c}\text { Levetiracetam } \\
\text { conc. in the } \\
\text { infant plasma } \\
\text { after } \\
\text { completion of } \\
\text { nursing }(\mu \mathrm{g} / \mathrm{ml})\end{array}$ & $\begin{array}{c}\text { Milk/plasma } \\
\text { ratio of } \\
\text { Levetiracetam }\end{array}$ & $\begin{array}{c}\text { Infant/maternal } \\
\text { plasma of } \\
\text { levetiracetam } \\
\text { conc. }\end{array}$ \\
\hline Minimum & 12 & 27 & 34 & 4 & 0.78 & 0.07 \\
\hline Maximum & 21 & 210 & 210 & 20 & 1.55 & 0.18 \\
\hline Mean & 14.1 & 90.5 & 93.9 & 11.0 & 1.12 & 0.1 \\
\hline SD & \pm 1.7 & \pm 14.3 & \pm 16.2 & \pm 1.4 & $\underline{\mathbf{\pm}}$ & $\underline{\mathbf{\pm}}$ \\
\hline
\end{tabular}

Table 6: Concentrations of levetiracetam measured in the maternal plasma and breast-milk of 14 lactating mothers. Figures are the minimum, maximum, mean, and $+S D$, by Tomson et al. [47].

This table shows that levetiracetam freely migrates into the breast-milk and the infant exposition to levetiracetam is limited.

Johannessen et al. [50] administered levetiracetam at doses of 1.5 to 3 grams daily to 7 lactating mothers and measured the concentration of levetiracetam in the maternal plasma and in the breast-milk on the third to fifth days after delivery. 


\begin{tabular}{|c|c|c|c|c|}
\hline Value & $\begin{array}{c}\text { Levetiracetam conc. } \\
\text { in maternal serum } \\
(\mu \mathrm{g} / \mathrm{ml})\end{array}$ & $\begin{array}{l}\text { Levetiracetam conc, } \\
\text { in breast-milk }(\mu \mathrm{g} / \mathrm{ml})\end{array}$ & $\begin{array}{c}\text { Levetiracetam conc. } \\
\text { in infant serum } \\
(\mu \mathrm{g} / \mathrm{ml})\end{array}$ & $\begin{array}{l}\text { Ratio of breast-milk } \\
\text { to maternal serum of } \\
\text { levetiracetam conc. }\end{array}$ \\
\hline Minimum & 62 & 68 & $<10$ & 0.87 \\
\hline Maximum & 175 & 153 & 15 & 1.04 \\
\hline Mean & 81.1 & 74.6 & 1.0 & 0.94 \\
\hline SD & \pm 17.0 & \pm 17.0 & \pm 0.07 & \pm 0.05 \\
\hline
\end{tabular}

Table 7: Concentrations of levetiracetam measured in the maternal plasma and breast-milk of 7 lactating mothers. Figures are the minimum, maximum, mean, and $+S D$, by Johannessen et al. [50].

This table shows that levetiracetam freely migrates into the breast-milk and the infant exposition to levetiracetam is limited.

Levetiracetam was administration to 5 lactating women and the mean umbilical cord serum to maternal serum ratio is 1.14 (range, 0.97 to 1.45 ). The mean milk to maternal serum concentration ratio of levetiracetam is 1.00 (range, 0.76 to 1.33 ) at 3 to 5 days after delivery. At sampling 2 weeks to 10 months after delivery, this ratio is similar and ranges from 0.85 to 1.38 . At 3 to 5 days after delivery, the infants had very low levetiracetam serum concentrations (range, $<10$ to $15 \mu \mathrm{M}$ ), a finding that persisted during continued breast-feeding. These data indicate an extensive migration of levetiracetam into the breast-milk [50]. Levetiracetam was administered to 20 lactating women and the trough breast-milk to serum ratio of levetiracetam is $0.98 \pm 0.20$, thus levetiracetam freely migrates into the breast-milk [51].

\section{Discussion}

Levetiracetam inhibits focal and secondary generalized tonic-clonic seizures in the kindling model but it is ineffective against maximum electroshock and pentylenetetrazol-induced seizures. In addition, levetiracetam inhibits $\mathrm{N}$-type $\mathrm{Ca}^{2+}$ channels and $\mathrm{Ca}^{2+}$ release from intracellular stores. Levetiracetam is rapidly and almost completely absorbed after oral administration and $95 \%$ of the drug and its inactive metabolite are excreted in the urine, $65 \%$ of which is unchanged drug, $24 \%$ of the drug is metabolized by hydrolysis of the acetamide group [1]. Levetiracetam may be administered orally or intravenously in infants [2] and in children [4] and in children the dose varies according to the child age and body-weight. Levetiracetam has been found efficacy and safe in infants and children [5-21] but levetiracetam may induce adverse-effects [4]. Levetiracetam is effective, safe, and well tolerated in treating neonatal seizures and epilepsy in infants [5-14] and in children [15-21]. The pharmacokinetics of levetiracetam have been studied in infants [22], in infants and children [23] and in children [24-25]. In infants, the central distribution volume is larger than the peripheral distribution volume [22]. Following oral administration to infants and children, levetiracetam is rapidly absorbed and the elimination half-life is $5.3 \pm 1.3$ hours suggesting that levetiracetam is rapidly eliminated [23]. In children, the levetiracetam elimination half-life is $6.0 \pm 1.1$ hours and the renal clearance is similar to the non-renal children suggesting that levetiracetam is eliminated by kidney and by other routes [24]. In children, aged 0.5 to 14 years, levetiracetam is rapidly absorbed following oral dosing and the mean total body clearance and distribution volume are $1.04 \mathrm{~L} / \mathrm{h}$ and $12.1 \mathrm{~L}$, respectively [25]. The prophylaxis with levetiracetam has been studied in infants and children [26-29]. Levetiracetam is effective as flunarizine in the prophylaxis of migraine in paediatric patients [26], levetiracetam and phenytoin have similar effectiveness for prevention of seizure induced by busulfan [27], levetiracetam and (fos) phenytoin are similarly effective in preventing early post-haemorrhagic seizures in infants and children [28], and prophylactic levetiracetam reduces the incidence of seizures in children after severe traumatic brain injury [29]. The treatment of infants and children with levetiracetam has been extensively studied [30-38]. Levetiracetam is similarly effective to phenobarbital in treating seizures but levetiracetam induces lower risk of adverse-effects [30].
Levetiracetam treats neonatal seizures in infants with hypoxic ischemic encephalopathy [31] and levetiracetam is an alternative therapeutic option in neonatal seizures [32, 33]. Levetiracetam is efficacious and welltolerated in the treatment of partial-onset seizures in infants and children [34], and levetiracetam successfully treats various types of epilepsy in very young children [35]. Levetiracetam, combined with sodium valproate, treats childhood epilepsy and does not increase clinical adverse-drug reactions [36], levetiracetam is more effective than carbamazepine in treating seizures in children [37], and levetiracetam treats epilepsy and is well tolerated in paediatric patients [38]. The trials with levetiracetam have been extensively studied in infants and children [39-46]. Levetiracetam successfully treats neonatal seizures and is a firstline anticonvulsant in infants with epilepsy [39], levetiracetam and phenytoin are similarly effective as a second-line antiseizure medication in paediatric epilepsy [40], levetiracetam prevents and treats paediatric epilepsy [41], levetiracetam is an effective anti-epileptic drug in children and adults with generalized or partial-onset refractory seizures [42], and levetiracetam is safe and efficacy in treating all types of epilepsy in children [43]. Levetiracetam has similar effects to phenytoin in treating children with status epilepticus resistant to benzodiazepine [44], levetiracetam is an appropriate alternative to phenytoin in treating paediatric convulsive status epilepticus [45], and levetiracetam is safe and effective agent for treating epilepsy in children [46]. Levetiracetam freely crosses the human placenta [47-50] and levetiracetam slowly decays in infant plasma [47], and levetiracetam freely migrates into the breast-milk [47-51].

In conclusion, levetiracetam treats focal and secondary generalized tonicclonic seizures. Levetiracetam is rapidly and almost completely absorbed after oral administration and $95 \%$ of the drug and its inactive metabolite are excreted in the urine $65 \%$ of which is unchanged drug and $24 \%$ of the drug is metabolized by hydrolysis of the acetamide group. Levetiracetam may be administered intravenously or orally to infants and children and in children the dose varies according to the child age and body-weight. Levetiracetam has been found efficacy and safe in infants and children but it may induce adverse-effects. The pharmacokinetics of levetiracetam have been studied in infants and in children and the levetiracetam elimination half-life is about 6 hours in infants and children and the renal clearance is similar to the non-renal clearance in children suggesting that levetiracetam is eliminated by kidney and by other routes. The prophylaxis, treatment, and trials with levetiracetam have been extensively studied in infants and children and levetiracetam freely crosses the human placenta and freely migrates into the breast-milk. The aim of this study is to review the clinical pharmacology of levetiracetam in infants and children.

\section{Conflict of interests}

The authors declare no conflicts of financial interest in any product or service mentioned in the manuscript, including grants, equipment, medications, employments, gifts, and honoraria.

This article is a review and drugs have not been administered to men or animals. 


\section{Acknowledgments}

The author thanks Dr. Patrizia Ciucci and Dr. Francesco Varricchio, of the Medical Library of the University of Pisa, for retrieving the scientific literature.

\section{References}

1. Smith MD, Metcalf CS, Wilcox KS. (2018). "Pharmacology of the Epilepsies". In The Goodman \& Gilman's. The Pharmacological Basis of the Therapeutics, Brunton Hilal-dandan LL, Knollmann BC, editors. Mc Graw Hill, $13^{\text {th }}$ Edition, USA, New York. 303-338.

2. Neonatal Formulary. (2020). "Levetiracetam": Oxford University Press. $8^{\text {th }}$ Edition, Great Clarendon Street, Oxford, OX2, 6DP, UK. 440-442.

3. Young TE, Mangum B. (2010). NEOFAX ${ }^{\circledR}$. "Levetiracetam". Thomas Reuters Clinical Editorial Staff, $23^{\text {rd }}$ Edition, Montvale, USA. 210-213.

4. The British National Formulary for Children. "Levetiracetam". Macmillan, $78^{\text {th }}$ Edition, Hampshire International Business Park, Hampshire, Lime Three Way, Basingstoke, Hampshire, UK. 2019-2020; 208-209.

5. Han JY, Moon CJ, Youn YA, Sung IK, Lee IG. (2018). Efficacy of levetiracetam for neonatal seizures in preterm infants. BMC Pediatr. 18(1): 131.

6. Arzimanoglou A, Lösch C, Garate P, Bentz J. (2016). Safety of levetiracetam among infants younger than 12 months--Results from a European multicenter observational study. Eur J Paediatr Neurol. 20(3): 368-375.

7. Cormier J, Chu CJ. (2013). Safety and efficacy of levetiracetam for the treatment of partial onset seizures in children from one month of age. Neuropsychiatr Dis Treat. 9(2): 295-306.

8. Liu B-K, Jiang L, Li X-J, Hong S-Q, Chen W, Hu Y. (2020). Efficacy and safety of levetiracetam in the off-label treatment of neonatal seizures. Int J Neurosci. 130(4): 336-342.

9. Karaoğlu P, Hız S, İşcan B, Polat AI, Ayanoğlu M, Duman N, et al. (2020). Intravenous Levetiracetam for Treatment of Seizures in Term and Preterm Neonates. J Pediatr Neurosci. 15(1): 15-20.

10. Arican P, Gencpinar P, Cavusoglu D, Dundar NO. (2018). Levetiracetam monotherapy for the treatment of infants with epilepsy. Seizure. 56(3): 73-77.

11. Venkatesan C, Young S, Schapiro M, Thomas C. (2017). Levetiracetam for the Treatment of Seizures in Neonatal Hypoxic Ischemic Encephalopathy. J Child Neurol. 32(2): 210-214.

12. Khan O, Cipriani C, Wright C, Crisp E, Kirmani B. (2013). Role of intravenous levetiracetam for acute seizure management in preterm neonates. Pediatr Neurol. 49(5): 340-343.

13. Ramantani G, Ikonomidou C, Walter B, Rating D, Dinger J. (2011). Levetiracetam: safety and efficacy in neonatal seizures. Eur J Paediatr Neurol. 15(1): 1-7.

14. Grosso S, Cordelli DM, Franzoni E, Coppola G, Capovilla G, Zamponi N, et al. (2007). Efficacy and safety of levetiracetam in infants and young children with refractory epilepsy. Seizure. 16(4): 345-350.

15. Kim JS, Lee JH, Hye Ryu W, Lim BC, Hwang H, Chae, J-H, et al. (2014). Effectiveness of intravenous levetiracetam as an adjunctive treatment in pediatric refractory status epilepticus. Pediatr Emerg Care. 30(8): 525-528.

16. Gallentine WB, Hunnicutt AS, Husain AM. (2009). Levetiracetam in children with refractory status epilepticus. Epilepsy Behav. 14(1): 215-218.
17. Aceves J, Khan O, Mungall D, Fonkem E, Wright C, Wenner A, et al. (2013). Efficacy and tolerability of intravenous levetiracetam in childrens. Front Neurol. 4: 120.

18. Goraya JS, Khurana DS, Valencia I, Melvin JJ, Cruz M, Legido A, et al. (2008). Intravenous levetiracetam in children with epilepsy. Pediatr Neurol. 38(3): 177-180.

19. Khongkhatithum C, Thampratankul L, Wiwattanadittakul N, Visudtibhan A. (2015). Intravenous levetiracetam in Thai children and adolescents with status epilepticus and acute repetitive seizures. Eur J Paediatr Neurol. 19(4): 429-434.

20. Giroux PC, Salas-Prato M, Théorêt Y, Carmant L. (2009). Levetiracetam in children with refractory epilepsy: lack of correlation between plasma concentration and efficacy. Seizure. 18(8): 559-563.

21. İşgüder R, Güzel O, Ağın H, Yılmaz Ü, Akarcan SE, Celik T, et al. (2014). Efficacy and safety of IV levetiracetam in children with acute repetitive seizures. Pediatr Neurol. 51(5): 688-695.

22. Merhar SL, Schibler KR, Sherwin CM, Meinzen-Derr J, Shi J, Balmakund T, et al. (2011). Pharmacokinetics of Levetiracetam in Neonates with Seizures. J Pediatr. 159(1): 152-154.

23. Glauser TA, Mitchell WG, Weinstock A, Bebin M, Chen D, Coupez R, et al. Pharmacokinetics of levetiracetam in infants and young children with epilepsy. Epilepsia. (2007). 48(6): 11171122.

24. Pellock JM, Glauser TA, Bebin EM, Fountain NB, Ritter FJ, Coupez RM, et al. (2001). Pharmacokinetic study of levetiracetam in children. Epilepsia. 42(12): 1574-1579.

25. Wang Y-H, Wang L, Lu W, Shang D-W, Wei M-J, Wu1 Y. (2012). Population pharmacokinetics modeling of levetiracetam in Chinese children with epilepsy. Acta Pharmacol Sin. 33(6): 845-851.

26. Rahman SM, Kundu GK, Fatema K, Akhter S, Rahman MM. (2018). Comparison between flunarizine and levetiracetam in paediatric migraine prophylaxis. Bangl Med J Khu. 51(1-2): 3539.

27. Floeter AE, McCune JS. (2017). Levetiracetam for the prevention of busulfan-induced seizures in pediatric hematopoietic cell transplantation recipients. J Oncol Pharm Pract. 23(5): 344-349.

28. Bansal S, Blalock D, Kebede T, Dean NP, Carpenter JL. (2014). Levetiracetam versus (fos)phenytoin for seizure prophylaxis in pediatric patients with intracranial haemorrhage. J Neurosurg Pediatr. 13(2): 209-215.

29. Kolf MJ, McPherson CC, Kniska KS, Luecke CM, Lahart MA, Pineda JA. (2020). Early Post-traumatic Seizure Occurrence in Pediatric Patients Receiving Levetiracetam Prophylaxis With Severe Traumatic Brain Injury. J Pediatr Pharmacol Ther. 25(3): 241-245.

30. Hooper RG, Ramaswamy VV, Wahid RM, Satodia P, Bhulani A. (2021). Levetiracetam as the first-line treatment for neonatal seizures: a systematic review and meta-analysis. Dev Med Child Neurol.

31. Venkatesan C, Young S, Schapiro M, Thomas C. (2017). Levetiracetam for the Treatment of Seizures in Neonatal Hypoxic Ischemic Encephalopathy. J Child Neurol. 32(2): 210-214.

32. Fürwentsches A, Bussmann C, Ramantani G, Ebinger F, Philippi $\mathrm{H}$, Pöschl J, et al. (2010). Levetiracetam in the treatment of neonatal seizures: a pilot study. Seizure. 19(3): 185-189.

33. Shoemaker MT, Rotenberg JS. (2007). Levetiracetam for the treatment of neonatal seizures. J Child Neurol. 22(1): 95-98.

34. Piña-Garza JE, Nordli DR Jr, Dietz Rating D, Yang $H$, Schiemann-Delgado J, Duncan B. (2009). Adjunctive levetiracetam in infants and young children with refractory partial-onset seizures. Epilepsia. 50(5): 1141-1149. 
35. Krief P, Kan L, Maytal J. (2008). Efficacy of levetiracetam in children with epilepsy younger than 2 years of age. J Child Neurol. 23(5): 582-584.

36. Zhao J, Sang Y, Zhang Y, Zhang D, Chen J, Liu X. (2019). Efficacy of levetiracetam combined with sodium valproate on pediatric epilepsy and its effect on serum miR-106b in children. Exp Ther Med. 18(6): 4436-4442.

37. Akhondian J, Ashrafzadeh F, Eslamiyeh H. (2020). Levetiracetam (levebel) Versus Carbamazepine Monotherapy for Focal Epilepsy in Children: A randomized clinical trial. Iran J Child Neurol. 14(2): 69-77.

38. Dooley M, Plosker GL. Levetiracetam. (2000). A review of its adjunctive use in the management of partial onset seizures. Drugs. 60(4): 871-893.

39. Falsaperla R, Mauceri L, Pavone P, Barbagallo M, Vitaliti G, Ruggieri M, et al. (2019). Short-Term Neurodevelopmental Outcome in Term Neonates Treated with Phenobarbital versus Levetiracetam: A Single-Center Experience. Behav Neurol. 3683548.

40. Angurana KS, Suthar R. (2021). Efficacy and Safety of Levetiracetam vs. Phenytoin as Second Line Antiseizure Medication for Pediatric Convulsive Status Epilepticus: A Systematic Review and Meta-Analysis of Randomized Controlled Trials. Trop Pediatr. 67(2).

41. Gan J, Ma D, Xiong T. (2019). Efficacy and safety of levetiracetam in children with epilepsy: protocol for an umbrella review of systematic reviews and meta-analyses of randomised controlled trials. BMJ Open. 9(7): 029811.

42. Chen D, Bian H, Zhang L. (2019). A meta-analysis of levetiracetam for randomized placebo-controlled trials in patients with refractory epilepsy. Neuropsychiatr Dis Treat. 15(4): 905917.
43. Zhang L, Wang C, Li W. (2018). A meta-analysis of randomized controlled trials on levetiracetam in the treatment of pediatric patients with epilepsy. Neuropsychiatr Dis Treat. 14(3): 769-779.

44. Dalziel SR, Furyk J, Bonisch M, Oakley E, Borland M, Neutze J, et al. (2017). A multicentre randomised controlled trial of levetiracetam versus phenytoin for convulsive status epilepticus in children (protocol): Convulsive Status Epilepticus Paediatric Trial (ConSEPT) - a PREDICT study. BMC Pediatr. 17(1): 152.

45. Lyttle MD, Rainford NEA, Gamble C, Messahel S, Humphreys A, Hickey H, et al. (2019). Levetiracetam versus phenytoin for second-line treatment of paediatric convulsive status epilepticus (EcLiPSE): a multicentre, open-label, randomised trial. Lancet. 25; 393(10186): 2125-2134.

46. Lagae L, Buyse G, Ceulemans B. (2005). Clinical experience with levetiracetam in childhood epilepsy: an add-on and mono-therapy trial. Seizure. 14(1): 66-71.

47. Tomson T, Palm R, Källén K, Ben-Menachem E, Söderfeldt B, Danielsson B, et al. (2007). Pharmacokinetics of levetiracetam during pregnancy, delivery, in the neonatal period, and lactation. Epilepsia. 48(6): 1111-1116.

48. López-Fraile IP, Cid AO, Juste AO, Modrego PJ. (2009). Levetiracetam plasma level monitoring during pregnancy, delivery, and postpartum: clinical and outcome implications. Epilepsy Behav. 15(3): 372-375.

49. Johannessen SI, Helde G, Brodtkorb E. (2005). Levetiracetam concentrations in serum and in breast-milk at birth and during lactation. Epilepsia. 46(5): 775-777.

50. Pennell PB. (2006). Is Breast-milk the Best for Babies of Mothers on Levetiracetam? Epilepsy Curr. 6(1): 22-24.

51. Dinavitser N, Kohn E, Berlin M, Brandriss N, Bar-Chaim A, Keidar R, et al. (2021). Levetiracetam in lactation: How much is excreted into human breast-milk? Br J Clin Pharmacol.

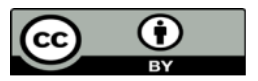

This work is licensed under Creative Commons Attribution 4.0 License
To Submit Your Article Click Here: Submit Manuscript

DOI: $10.31579 / 2768-0487 / 054$
Ready to submit your research? Choose Auctores and benefit from:

$>$ fast, convenient online submission

$>$ rigorous peer review by experienced research in your field

$>$ rapid publication on acceptance

$>$ authors retain copyrights

$>$ unique DOI for all articles

$>$ immediate, unrestricted online access

At Auctores, research is always in progress.

Learn more auctoresonline.org/journals/journal-of-clinical-andlaboratory-research 